\title{
Distribution of Heme Oxygenase Isoforms in Rat Liver Topographic Basis for Carbon Monoxide-mediated Microvascular Relaxation
}

\author{
Nobuhito Goda, ${ }^{\star}$ Kensuke Suzuki, $\|$ Makoto Naito, ${ }^{\ddagger}$ Shinji Takeoka, ${ }^{\S}$ Eishun Tsuchida, ${ }^{\S}$ Yuzuru Ishimura, ${ }^{\star}$ Takuya Tamatani, \\ and Makoto Suematsu* \\ *Department of Biochemistry and Department of Obstetrics and Gynecology, School of Medicine, Keio University, Tokyo 160; ${ }^{\ddagger}$ Second \\ Department of Pathology, Niigata University School of Medicine, Niigata; ${ }^{\S}$ Department of Polymer Chemistry, Waseda University, Tokyo;

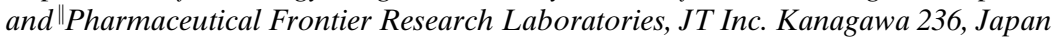

\begin{abstract}
Carbon monoxide (CO) derived from heme oxygenase has recently been shown to play a role in controlling hepatobiliary function, but intrahepatic distribution of the enzyme is unknown. We examined distribution of two kinds of the heme oxygenase isoforms (HO-1 and $\mathrm{HO}-2)$ in rat liver immunohistochemically using monoclonal antibodies. The results showed that distribution of the two isoforms had distinct topographic patterns: HO-1, an inducible isoform, was observed only in Kupffer cells, while HO-2, a constitutive form, distributed to parenchymal cells, but not to Kupffer cells. Both isoforms were undetectable in hepatic stellate cells and sinusoidal endothelial cells. Of the two isoforms, HO-2 in the parenchymal cell rather than HO-1 in the Kupffer cell, appears to play a major role in regulation of microvascular tone. In the perfused liver, administration of $\mathrm{HbO}_{2}$, a CO-trapping reagent that can diffuse across the fenestrated endothelium into the space of Disse, elicited a marked sinusoidal constriction, while administration of a liposome-encapsulated $\mathrm{Hb}$ that cannot enter the space had no effect on the microvascular tone. These results suggest that $\mathrm{CO}$ evolved by $\mathrm{HO}-2$ in the parenchymal cells, and, released to the extrasinusoidal space, served as the physiological relaxant for hepatic sinusoids. (J. Clin. Invest. 1998. 101:604-612.) Key words: heme oxygenase-1 1 heme oxygenase-2 $\bullet$ hepatic stellate cells $•$ Kupffer cells• hemoglobin
\end{abstract}

\section{Introduction}

Physiological degradation of heme (iron-protoporphyrin IX) into biliverdin, iron, and carbon monoxide $(\mathrm{CO})^{1}$, is mediated by heme oxygenase (HO, EC1.14.99.3) which consists of two

Address correspondence to Associate Professor Makoto Suematsu, M.D., Ph.D., Department of Biochemistry, School of Medicine, Keio University, 35 Shinanomachi, Shinjuku-ku, Tokyo 160, Japan. Phone: +8-3355-2827; FAX: +81-3-3358-8138; E-mail: msuem@mc.med.keio. ac.jp

Received for publication 28 July 1997 and accepted in revised form 5 December 1997.

1. Abbreviations used in this paper: $\mathrm{CO}$, carbon monoxide; $\mathrm{HO}$, heme oxygenase; HRP, horseradish peroxidase; rHO, rat heme oxygenase; $\mathrm{ZnPP}$, zinc protoporphyrin IX.

J. Clin. Invest.

(C) The American Society for Clinical Investigation, Inc. 0021-9738/98/02/0604/09 \$2.00

Volume 101, Number 3, February 1998, 604-612

http://www.jci.org distinct isoenzymes called HO-1 (1) and HO-2 (2). HO-1, also known as the heat shock protein-32, is induced by a variety of stressors such as hyperthermia (3), cytokines (4), and intake of heavy metals (5). This isoform is considered to be present in spleen, a major organ for destruction of senescent erythrocytes, and in liver stimulated with endotoxin (6) or ischemia reperfusion (7). On the other hand, $\mathrm{HO}-2$ is a constitutive form known to be abundant in brain, testis, and unstimulated liver of rodents and humans as reported previously (8).

Recently, several lines of evidence have indicated that the heme oxygenase reaction serves as a key mechanism to maintain the integrity of physiological function of organs such as liver through the action of the reaction products $\mathrm{CO}$ and bilirubin. We have shown that in the perfused rat liver, zinc protoporphyrin IX (ZnPP), a heme oxygenase inhibitor, elicits a marked increase in the vascular resistance as a consequence of sinusoidal constriction $(9,10)$. Furthermore, the $\mathrm{ZnPP}$ administration turned out to induce bile acid-dependent choleresis that coincided with depletion of the venous $\mathrm{CO}$ flux and biliary excretion of bilirubin, another product of heme degradation (11). Therefore, the results have suggested that CO generated by heme oxygenase serves as a regulator of hepatobiliary functions under physiological conditions. On the other hand, bilirubin scavenges various oxidants such as hydroxyl radical and singlet oxygen, and is thus considered an endogenous antioxidant that protects cells from oxidative insults $(12,13)$.

In an attempt to understand the aforementioned roles of heme oxygenase, we investigated the intrahepatic distribution of HO-1 and HO-2 using newly developed mAbs against these isozymes. The results indicated distinct distribution patterns of these isozymes among the liver cells, and thus provided a microtopographic basis for the mechanism of CO-mediated sinusoidal relaxation.

\section{Methods}

Animals. Male Wistar rats (260-300 g) were obtained from Saitama Animal Laboratory (Saitama, Japan). Female BALB/c (6-10 wk old) and CRJ; CD-1nu mice (7 wk old) were purchased from Charles River Japan Inc. (Atsugi, Japan). All animals were allowed free access to laboratory chow and tap water. Rats were anesthetized intraperitoneally with pentobarbital sodium $(50 \mathrm{mg} / \mathrm{kg})$, and the liver, spleen, and testis were then excised to collect samples for Western blotting analysis and immunohistochemistry. In separate sets of experiments, rats were pretreated with intraperitoneal injection of LPS (O-111B4, $4 \mathrm{mg} / \mathrm{kg}$ ) $6 \mathrm{~h}$ before the sample collection.

Transformant cells expressing HO-1 and -2 . Rat hepatocytes were isolated and cultured according to the previous method (14). Total cellular RNAs were extracted using ISOGEN (Nippon Gene, Tokyo, Japan) from the cells pretreated with or without heat treatment for $4 \mathrm{~h}$ at $42^{\circ} \mathrm{C}$. The first-strand cDNAs were synthesized with the mixture of oligo $(\mathrm{dT})_{20}$ primers and random hexamers $\left(\mathrm{pd}[\mathrm{N}]_{6}\right)$ using reverse transcriptase. PCR primers (rHO-1: $5^{\prime}$-d[GCC TGA ACT AGC 
CCA ATT GCG CGA TGG AGC GC]-3', 5'-d[CTC TGG GGG CCA AGT CGA CAT TTA CAT GGC AT]-3'; rHO-2: 5'-d[AGG GCA GCA CAA AGA ATT CAG CAA CAA ATG TCT]-3', 5'-d[ATG CAA ACA ACA TGT CGA CTC CTT CAC ATG TA] $-3^{\prime}$ ) were synthesized based on the nucleotide sequences of rat HO-1 (rHO-1) and -2(rHO-2) reported by Shibahara et al. (1) and Rotenberg and Maines (15). Using these primers, $\mathrm{rHO}-1$ and -2 were amplified from first-strand cDNAs based on the PCR using AmpliWax PCR Gem 100 (Takara Biomedicals, Tokyo, Japan). The pEFneo plasmid vector containing the EF-1a promoter was used to express rHO-1 and -2 (16). An adaptor was attached to the Sal I site at the $3^{\prime}$ end of both PCR products, resulting in construction of the Not I site which was present in multiple cloning sites of the pEFneo plasmid vector. The resulting PCR products were sequenced to confirm their identities, and were named pEFneo-rHO-1 and pEFneo-rHO-2, respectively. The expression plasmid DNAs, pEFneo-rHO-1 and -2, were transfected into WR19L cells (mouse T cell line) by electroporation (17). The transfected cells, designed as WR19L-rHO-1 and-HO-2, were cultured in RPMI 1640 supplemented with $10 \%$ FCS under 5\% $\mathrm{CO}_{2}$. After the 24-h incubation, geneticin (Gibco-BRL, Gaithersburg, $\mathrm{MD}$ ) was added to the culture medium at a final concentration of $0.9 \mathrm{mg} / \mathrm{ml}$ to obtain stable transformants.

$\mathrm{HO}$ activities in the transformants. Heme oxygenase activities in transformants were determined by measuring bilirubin formation. The cells were harvested and washed twice with PBS at $\mathrm{pH}$ 7.0. To remove insoluble fraction, the cells were lysed in 4 volumes of $1 \%$ nonidet P-40 solution containing $150 \mathrm{mM} \mathrm{NaCl}$, phenylmethylsulfonyl fluoride $(1 \mathrm{mM})$, and $50 \mathrm{mM}$ Tris $\mathrm{HCl}(\mathrm{pH} 8.0)$ for $30 \mathrm{~min}$ on ice. The supernatants were collected by centrifugation at $10,000 \mathrm{~g}$ for $15 \mathrm{~min}$. The reaction mixture contained the following in a final volume of $300 \mu \mathrm{l}$ : glucose 6-phosphate $(1 \mathrm{mM})$, glucose 6-phosphate dehydrogenase (0.167 U/ml), NADP $(0.8 \mathrm{mM})$, hemin $(15 \mu \mathrm{M}), \mathrm{MgCl}_{2}(2 \mathrm{mM})$, NADPH-cytochrome P450 reductase $(0.01 \mathrm{mg} / \mathrm{ml}$; Gentest, Woburn, MA), rat liver cytosol (3.3 $\mathrm{mg}$ protein/ $\mathrm{ml}$ ), potassium phosphate buffer ( $27 \mathrm{mM}, \mathrm{pH} 7.4$ ), and the supernatant from the transformant cells. Incubation was carried out at $37^{\circ} \mathrm{C}$ for $30 \mathrm{~min}$. An equal volume of chloroform was added to the reaction mixture to stop the reaction, and bilirubin generated was extracted into the chloroform fraction. After centrifugation at $10,000 \mathrm{~g}$ for $15 \mathrm{~min}$, amounts of bilirubin in the chloroform extract was examined as previously reported by Yoshida and Kikuchi (18).

Hybridomas producing the $m A$ bs against rat heme oxygenase isoforms. The foot pads of 6 -wk-old female BALB/c mice were injected every week with $1 \mathrm{mg}$ protein of the microsomal fraction obtained from WR19L-rHO-1 and -HO-2, emulsified the first time with Freund's complete adjuvant, and the rest with the incomplete adjuvant. The immunization was repeated 5-10 times. $48 \mathrm{~h}$ after the last immunization, bilateral inguinal and parietal abdominal lymph nodes of immunized mice were harvested, and B lymphocytes were fused with mouse myeloma PAI cells in the ratio of $1: 3-5$ in $50 \%$ polyethylene glycol 4000 (Boehringer Mannheim, Mannheim, Germany). Hybridomas were cultured in ASF104 medium (Ajinomoto, Tokyo, Japan) containing $10 \%$ FCS and HAT (hypoxanthine, aminopterin, and thymidine) medium for $2 \mathrm{wk}$.

Selection of hybridomas producing mAbs against rHO-1 and -2 was carried out by examining the specific immunoreactivity of the supernatant fraction of their culture medium with membrane-permeabilized WR19L cells that expressed $\mathrm{rHO}-1$ and -2 , respectively. To this end, WR19L cells expressed rHO-1 and their wild-type was collected and fixed with $2 \%$ paraformaldehyde for $10 \mathrm{~min}$ at $4^{\circ} \mathrm{C}$ in PBS at $\mathrm{pH}$ 7.4. These cells were washed twice with PBS, and were blocked for 20 min at $4^{\circ} \mathrm{C}$ in RPMI 1640 supplemented with $10 \%$ FCS. The cells were then incubated with the supernatants of the hybridomas and $0.5 \%$ saponine in the same plates for $30 \mathrm{~min}$ at $4^{\circ} \mathrm{C}$. After washing twice with PBS, these cells were further incubated with sheep anti-mouse $\mathrm{F}\left(\mathrm{ab}^{\prime}\right)_{2}$ fragments of IgG conjugated with fluorescein (Organan-Teknika-Cappel, Durham, NC) for $30 \mathrm{~min}$ at $4^{\circ} \mathrm{C}$. After the rinse with PBS, the cells served as samples for the analysis using an EPICS flow cytometer (Coulter Electronics, Hialeah, FL). To obtain a single clone specifically producing the desired $\mathrm{mAb}$, subcloning of the hybridomas was further carried out by dilution of the cell number. A similar protocol was applied to screen the hybridomas that generated anti-rHO-2 mAbs. Finally, the anti-rHO-1 and $-2 \mathrm{mAbs}$ used in this study were named GTS-1 and GTS-2, respectively.

Purification and isotyping of monoclonal antibodies. Ascites were elicited in 8-wk-old female CRJ; CD-1nu mice that were pretreated with 2, 6,10,14-tetramethyl pentadecane by intraperitoneal injection of a desired hybridoma at a dose of $2 \times 10^{6}$ cells/mouse. The ascitic fluid was collected, and the mAbs were purified by sequential precipitation with caprylic acid and $45 \%$ ammonium sulfate as previously described (19). The purity of the mAbs was assessed by SDS-PAGE. The subclasses of purified mAbs were determined by a mouse monoclonal isotyping kit (RPN 29; Amersham International, Little Chalfont, UK).

Western blot analysis. Microsomal fractions isolated from spleen, liver, and testis of rats were subjected to Western blot analyses. Soluble fractions derived from stable transformant cells pretreated with $1 \%$ Nonidet P-40 solution served as the positive control samples. After denaturing, these proteins were subjected to $10 \%$ SDS-PAGE and then transferred to an Immobilon polyvinylidene difluoride transfer membrane (Daiichi Pure Chemicals, Tokyo, Japan). The membrane was blocked with Block-Ace (Dainippon Pharm. Co., Osaka, Japan) for at least for $3 \mathrm{~h}$, and was followed by incubation with either GTS- 1 or GTS-2 at $1 \mu \mathrm{g} / \mathrm{ml}$ overnight at $4^{\circ} \mathrm{C}$. After washing with PBS containing $0.1 \%$ Tween 20 , the membrane was immersed in a biotinylated anti-mouse IgG F $\left(\mathrm{ab}^{\prime}\right)_{2}$ fragment (RPN 1061; Amersham International) diluted in PBS containing 1\%BSA. The samples were then treated with avidin and horseradish peroxidase (HRP)-conjugated biotin according to manufacturer's protocol (Vectastain Elite ABC kit; Vector Laboratories, Inc., Burlingame, CA). Chemiluminescence associated with the antigen-specific HRP reaction was visualized by the Molecular Imager (GS-525, Nippon Bio-Rad. Co., Tokyo, Japan) and the ECL detection kit (Amersham International). The Western blot analysis was repeated to confirm reproducibility using the samples collected from at least three individual rats.

Immunohistochemistry. Rat spleen, liver, and testis were fixed for $4 \mathrm{~h}$ at $4^{\circ} \mathrm{C}$ in periodate-lysine-paraformaldehyde solution. The samples were washed sequentially for $4 \mathrm{~h}$ with PBS containing 10, 15, and $20 \%$ sucrose, and were embedded in OCT compound (Miles Laboratories, Elkhart, IN). In some experiments, fresh-frozen sections from these organs were prepared and fixed with acetone. The sections $(10-\mu \mathrm{m}$ thickness) were treated with normal horse serum to minimize nonspecific staining. These tissues were incubated with mAbs GTS-1 or GTS-2 dissolved in 1\% BSA/PBS at a final concentration of $1 \mu \mathrm{g} / \mathrm{ml}$ for at least $2 \mathrm{~h}$ at $25^{\circ} \mathrm{C}$ or overnight at $4^{\circ} \mathrm{C}$. After several washes with PBS, the sections were stained with biotinylated anti-mouse IgG for $1 \mathrm{~h}$ (Vectastain Elite ABC kit; Vector Laboratories, Inc.). To prevent endogenous peroxidase reactions, the samples were pretreated with $0.3 \% \mathrm{H}_{2} \mathrm{O}_{2}$ in cold methanol for $30 \mathrm{~min}$, and were subsequently incubated with avidin and HRP-conjugated biotin for $30 \mathrm{~min}$. Finally, $0.1 \mathrm{mg} / \mathrm{ml}$ of 3, 3'-diaminobenzidine (DAB) tetrahydrochloride were applied to sections for $5 \mathrm{~min}$. The sections were counterstained with methyl green after fixation with $20 \%$ formaldehyde for $20 \mathrm{~min}$, and slides were coverslipped with aqueous mounting medium. To confirm the specificity of immunohistochemical localization by the antibodies, the antibodies preabsorbed with an excess of adequate antigens in advance were used. In separate sets of experiments, sections of the liver were double-stained by a method using DAB and nickel chloride to identify different types of nonparenchymal cells (20). To this end, anti-rat macrophage mAb Ki-M2R (BMA Biomedicals Ltd., Augst, Switzerland) and antidesmin II mAb (BioScience Products AG, Emmenbrucke, Switzerland) were used to stain Kupffer cells and hepatic stellate cells, respectively. By these protocols, cells reacting only with the initial primary Ab (GTS-1 or -2) stained light brown, while those reacting with the second primary $\mathrm{Ab}$ stained bright purple. When reacting simultaneously with both primary Abs, the cells were identified as those stained dark purple. 
Isolated perfused liver preparation. The livers of male Wistar rats were excised and perfused with $\mathrm{Hb}$-free and albumin-free Krebs Ringer solution $\left(\mathrm{pH} 7.4,37^{\circ} \mathrm{C}\right)$ gassed with carbogen $\left(95 \% \mathrm{O}_{2}, 5 \%\right.$ $\mathrm{CO}_{2}$ ) according to our methods described previously $(10,21)$. The perfusate contained $30 \mu \mathrm{M}$ sodium taurocholate, and was pumped through the liver at a constant flow rate of $4.0 \mathrm{ml} / \mathrm{min} / \mathrm{g}$ liver. The preparation allowed us to examine the vasoactive responses in sinusoids while simultaneously monitoring the whole organ vascular resistance, as described elsewhere $(10,11)$.

Determination of $\mathrm{CO}$ generated by isolated cultured hepatocytes. Primary cultured rat hepatocytes were prepared by digesting the liver with type IV collagenase (Wako Pure Chemical Industries, Ltd., Osaka, Japan) according to the previous method (14). To estimate the rate of heme degradation in the isolated cultured hepatocytes, concentrations of $\mathrm{CO}$ were determined in the culture medium. To this end, the hepatocyte suspension $\left(5 \times 10^{6} \mathrm{cells} / \mathrm{ml}\right)$ was incubated in a specially arranged double-lumen bioreactor as described previously (mini PERM; Heraeus Instruments, Inc., Hatz, Germany; 22). $2 \mathrm{ml}$ of the culture medium was collected $2 \mathrm{~h}$ after the start of culture, and was used as a sample to determine $\mathrm{CO}$. $\mathrm{CO}$ in the sample medium was determined by Mb-assisted spectrophotometry as described elsewhere (10).

Preparation of $\mathrm{Hb}$ and liposome-encapsulated $\mathrm{Hb}$. To examine the role of endogenously generated $\mathrm{CO}$ in regulating the steady-state vascular tone in the liver, free and liposome-encapsulated Hbs, hereafter designated as free $\mathrm{Hb}$ and $\mathrm{HbV}$, respectively, were used as a tool to trap $\mathrm{CO}$ in and around the sinusoidal space. Free $\mathrm{Hb}, \mathrm{HbV}$, and met $\mathrm{Hb}$, a control tool that can scavenge $\mathrm{NO}$ but not $\mathrm{CO}$, were prepared using outdated human erythrocytes as described previously $(23,24)$. The distribution of the diameter of the $\mathrm{HbV}$ was measured by a light-scattering particle analyzer (Submicron Particle Analyzer N4-SD; Coulter). The mean value of the diameter of $\mathrm{HbV}$ used in this study was $\sim 250 \mathrm{~nm}$. Previous histochemical studies (25) revealed that when administered into the systemic circulation, $\mathrm{HbV}$ with this size diameter was partly captured in tissue macrophages including Kupffer cells, but did not enter the hepatic parenchyma. On the other hand, free $\mathrm{Hb}$ was readily trapped by the parenchymal cells because of the presence of fenestration in sinusoidal endothelium, the diameter of which ranges from 100 to $150 \mathrm{~nm}(26,27)$. Both free $\mathrm{Hb}$ and $\mathrm{HbV}$ were used for experiments within $10 \mathrm{~d}$ after completing the preparation procedures. These samples were added in the perfusate at $1.5 \mathrm{~g} / \mathrm{dl}$ in $\mathrm{Hb}$ concentrations, the value equivalent to $\sim 10 \%$ of the physiological concentration in rat blood samples.

Microangiography of sinusoids in perfused liver. To examine whether free $\mathrm{Hb}$ and $\mathrm{HbV}$ alter the diameter of sinusoids by an unknown mechanism, digital microangiography in the perfused liver preparation was carried out as described previously $(10,28)$. To obtain a quality of the microvascular images, real-time laser confocal imaging system was applied to intravital microscopy according to our recent method (29). The surface of the perfused liver was observed through an inverted-type intravital microscope assisted by a line-scan laser confocal imager (Insight/TMD300; Meridian Instrs., Inc., Okemos, $\mathrm{MI})$ and the hepatic microcirculation was visualized by a silicon intensified target imaging camera (C2400-08; Hamamatsu Photonics, Hamamatsu City, Japan). To visualize the hepatic sinusoidal vessels, $100 \mu \mathrm{l}$ of $1 \%$ FITC-dextran solution was injected transportally every 5 min after the start of experiments, and the microvasculature was visualized by epi-illuminating at $488 \mathrm{~nm}$ using an argon laser light source. This system also allowed us to examine the topographic relationship between the sites of sinusoidal constriction and those of hepatic stellate cells, the liver-specific pericytes, by visualizing their vitamin A autofluorescence under epi-illuminating at $360 \mathrm{~nm}(10,30)$. Imaging of vitamin A-associated autofluorescence was carried out right before the start of FITC-dextran transportal injection. Recording intrahepatic vitamin A autofluorescence also helped us to examine whether the FITC-dextran-assisted microangiography was carried out at identical depths of focus among a series of microfluorographs taken at different times: When topographic patterns of the hepatic stellate cells in a field of interest were different among the images recorded in the same preparation, a series of FITC-dextranassisted microvascular images were discarded from the data analysis for measurements of sinusoidal diameters. The microangiographs were digitally processed, and were used for morphometrical analysis of the diameter changes as described previously (10). In brief, measurements of the diameter were carried out every $10 \mu \mathrm{m}$ along the longitudinal axis of sinusoids from the most efferent sites adjacent to central venules to the afferent sites. This procedure gave $\sim 20-30$ measurements for each sinusoid. At least 15 sinusoids were evaluated in a single experiment.

\section{Results}

Monoclonal antibodies against rat heme oxygenase. To verify immunoreactive specificity of mAbs against rHO-1 (GTS-1) and -2 (GTS-2), flow cytometry and Western blotting analysis were carried out using the stable transformants that expressed rHO-1 or -2 proteins as described in Methods. As shown in Fig. $1 A$, GTS-1 stained WR19L-rHO-1 cells positively, while it stained neither mock-transfected WR19L cells nor WR19LrHO-2 cells. On the other hand, WR19L-rHO-2 cells exhibited a positive immunostaining by GTS-2, whereas the mock-transfected cells and the WR19L-rHO-1 cells displayed negative staining, indicating a paucity of cross-reaction between the two mAbs as to recognition of the heme oxygenase isoforms. These findings were confirmed by Western blotting analysis (Fig. 1 B): GTS-1 and GTS-2 exhibited their specific immunoreactivities to $\mathrm{rHO}-1$ and -2 on molecular sizes of $32 \mathrm{kD}$ and
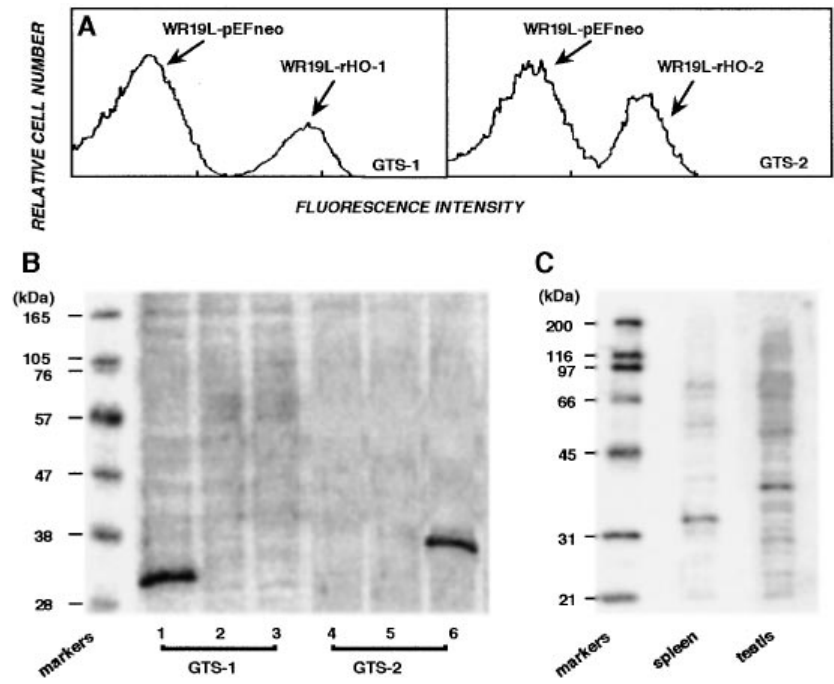

Figure 1. Characterization of newly developed monoclonal antibodies against rat $\mathrm{HO}$ isoforms. $(A)$ Flow cytometric analysis to examine specific binding of mAbs GTS- 1 and -2 to WR19L cells expressing rHO-1 and rHO-2, respectively. (B) Western blotting analysis showing the specific binding of mAbs GTS-1 and -2 to cell lysates extracted from the stable transformants WR19L-rHO-1 and WR19L-rHO-2. Lanes 1 and 4, WR19L-rHO-1; lanes 2 and 5, WR19L-pEFneo; lanes 3 and 6 , WR19L-rHO-2. Note that GTS-1 and -2 specifically recognize single bands at $32 \mathrm{kD}$ and $36 \mathrm{kD}$, respectively. $(C)$ Western blotting analysis showing the binding of mAbs GTS- 1 and -2 to microsomal fractions ( $10 \mu \mathrm{g}$ per lane) isolated from rat spleen and testis, respectively. Note the preferential expression of $\mathrm{HO}-1$ in spleen and $\mathrm{HO}-2$ in testis. 

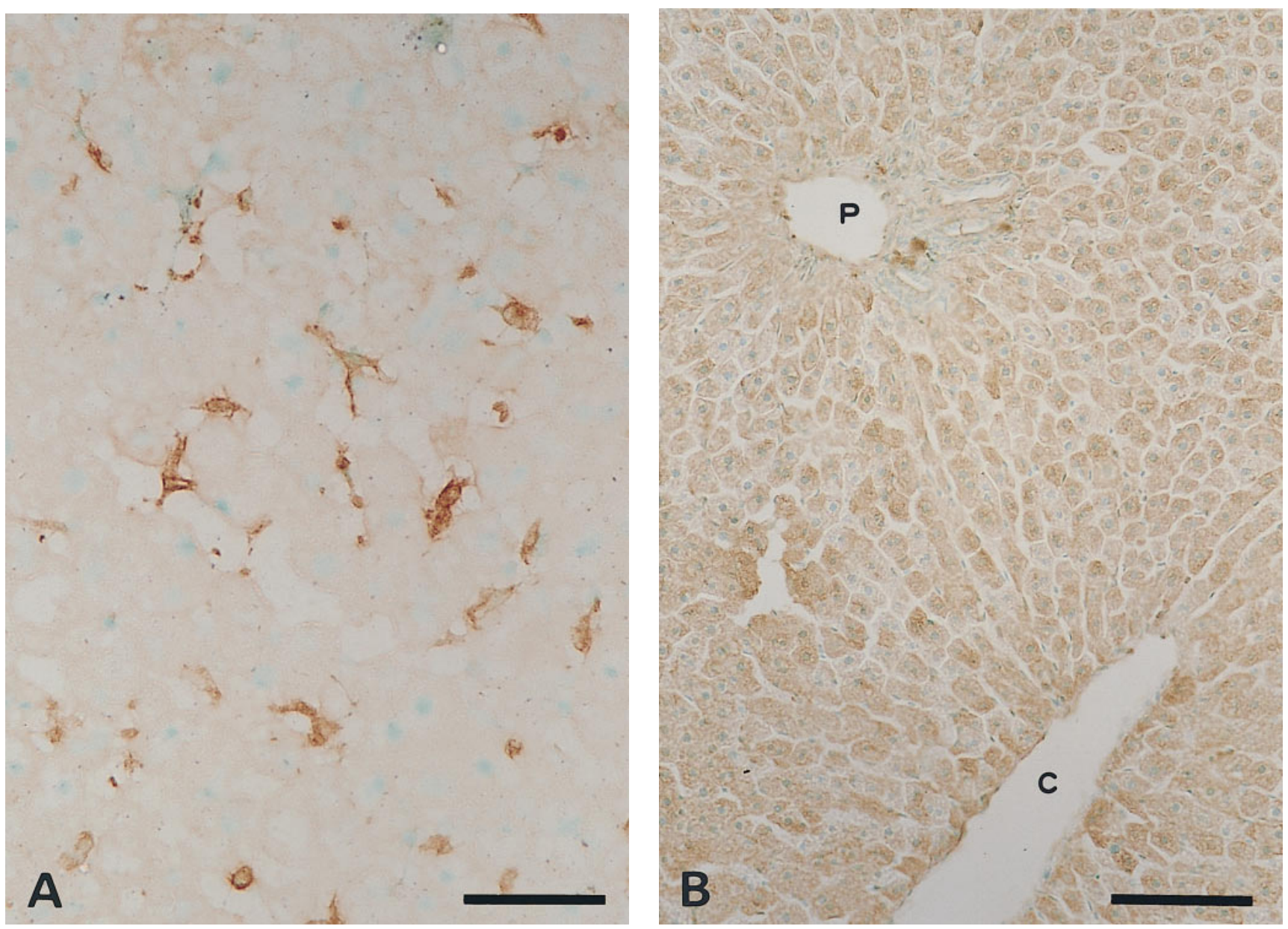

Figure 2. Expression of HO-1 and HO-2 in the normal rat liver. The 10- $\mu$ m-thick sections were immunostained with GTS-1 $(A)$ and GTS-2 $(B)$. $P$ and $\mathrm{C}$ denote portal and central venules, respectively. Bars represent $50 \mu \mathrm{m}$ and $100 \mu \mathrm{m}$ in $A$ and $B$, respectively.

$36 \mathrm{kD}$, respectively. We also examined adequacy of the use of these mAbs for Western blotting analysis using the tissue lysates collected from rats. Fig. $1 C$ illustrates representative data using spleen and testis, which are known to be abundant sources of HO-1 and HO-2, respectively $(13,31)$. As seen, GTS-1 and GTS-2 specifically recognized the presence of the two isoforms. These results indicate that, under both native and denatured conditions, these two mAbs can recognize their own counterpart antigen without displaying notable crossreactivities.

Expression of $\mathrm{HO}-1$ and $\mathrm{HO}-2$ in the liver. Immunohistochemical analysis in the liver disclosed different topographic patterns in distribution of the two isozymes. First, HO-1 distributed in a relatively small number of cells that scattered over the entire lobule (Fig. 2 A). These HO-1-positive cells were characterized by their irregular and dendritic shapes, and by protrusion of their cytoplasm towards sinusoidal spaces, suggesting the presence of HO-1 in Kupffer cells. On the other hand, hepatocytes exhibited little staining, if any. By contrast, HO-2 occurred in the parenchymal cells and distributed homogeneously among the entire lobule, while nonparenchymal cells displayed practically no staining (Fig. 2 B). We examined the specificity of $\mathrm{mAb}$ binding to the corresponding antigens by preabsorbing with an excess of $\mathrm{rHO}-1$ or $\mathrm{rHO}-2$ protein, re- sulting in the absence of detectable immunostaining in each case (data not shown).

We further attempted to determine specific cell types that express HO-1 among the nonparenchymal cells. The HO-1 distribution in Kupffer cells was demonstrated by staining the same section simultaneously with GTS-1 and the antitissue macrophage mAb Ki-M2R. A majority of the cells stained dark brown, and indicated superimposition of the two colors; that is, light brown (GTS-1) and purple (Ki-M2R; Fig. $3 A$ ). When hepatic stellate cells were stained purple with the antidesmin Ab, it became clear that the HO-1-positive cells that were recognized as those stained brown were dissociated from desmin-positive cells, indicating that hepatic stellate cells exhibited little if any HO-1 staining (Fig. $3 \mathrm{~B}$ ). These findings indicate that Kupffer cells constitute a major cellular compartment responsible for intrahepatic $\mathrm{HO}-1$ expression.

Intrahepatic distribution of HO-1 exhibited quite different pictures when the liver was prestimulated with LPS, an inducer of this enzyme. The liver exposed to the 6-h pretreatment revealed that HO-1 not only occurred in tissue macrophages, but was also induced markedly in hepatocytes (Fig. $4 A$ ). On the other hand, as seen in Fig. $4 \mathrm{~B}$, HO-2 staining did not display any notable changes as compared with the control liver illustrated in Fig. 2 B. These results indicate that Kupffer cells and 

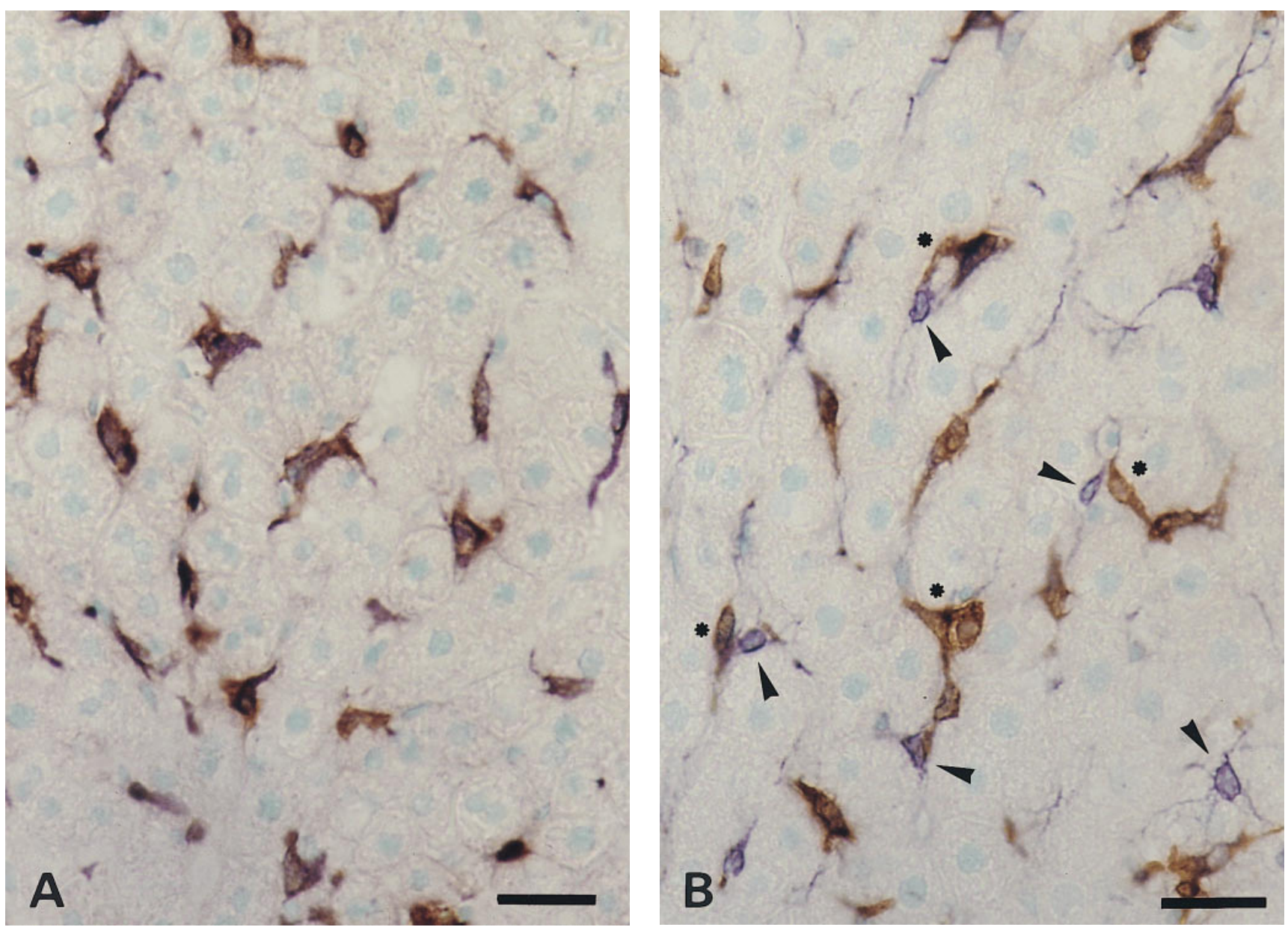

Figure 3. Characterization of nonparenchymal cells expressing HO-1 in the rat liver using the double immunohistochemical staining method. In $A$, the section was double-immunostained with GTS-1, an anti-rHO-1 mAb (brown), and with Ki-M2R, an mAb recognizing tissue macrophages (light purple). Colocalization of these two colors can be recognized by the dark brown color. In B, the section was stained with GTS-1 (light brown, asterisks) and then with an anti-desmin II mAb that recognizes hepatic stellate cells (purple, arrows). Bar, $50 \mu \mathrm{m}$ in both panels.

hepatocytes constitute major cellular components that express the inducible HO isozyme in the endotoxin-treated liver.

CO generation in isolated hepatocytes. Table I shows the release of $\mathrm{CO}$ and bilirubin in isolated rat hepatocytes cultured in the double-lumen bioreactor. In the control, the rate of $\mathrm{CO}$ production in the hepatocytes was $27 \mathrm{nmol} / \mathrm{h} / 10^{8}$ cells during the initial 1-h period of incubation. When $\mathrm{ZnPP}$ was added in the medium at a final concentration of $1 \mu \mathrm{M}, \mathrm{CO}$ became undetectable, at least during the initial incubation period, showing that hepatocytes were able to generate $\mathrm{CO}$ through the heme oxygenase reaction. The average flux of $\mathrm{CO}$ from the hepatocyte suspension estimated on the basis of assumption that $1 \mathrm{~g}$ of wet liver tissue containing $1 \times 10^{8}$ hepatocytes (32) was $\sim 0.45 \mathrm{nmol} / \mathrm{min} / \mathrm{g}$ liver, indicating that the cellular CO flux is comparable to that determined in the venous perfusate collected from the perfused liver (10). These results suggest that hepatocytes constitute a major component for endogenous $\mathrm{CO}$ generation in the perfused liver.

Vasoconstrictive effects of free and liposome-encapsulated $\mathrm{Hb}$ in perfused liver. Fig. 5 illustrates time history of alterations in the whole organ vascular resistance elicited by administration of free $\mathrm{HbO}_{2}$ or $\mathrm{HbV}-\mathrm{O}_{2}$ in perfused rat liver. As seen, immediately after the start of $\mathrm{HbO}_{2}$ administration, the resistance increased markedly, showing a $25 \%$ elevation as compared with that in the steady-state conditions. When the perfusate was replaced by the $\mathrm{Hb}$-free buffer at $15 \mathrm{~min}$, the increased resistance decreased gradually and reached the control level at $30 \mathrm{~min}$, indicating that the $\mathrm{HbO}_{2}$-induced vascular response is reversible. On the other hand, metHb, a reagent that could scavenge NO but not $\mathrm{CO}$, did not alter the vascular resistance, suggesting that $\mathrm{CO}$ plays a major role in lowering the

Table I. Production of CO by Isolated Rat Hepatocytes Cultured in a Double Lumen Bioreactor

\begin{tabular}{lc} 
Groups & $\mathrm{CO}$ \\
\hline & $n m o l / h / 10^{8}$ hepatocyte \\
Control & $27.5 \pm 5.0$ \\
ZnPP & $3.8 \pm 0.8^{*}$
\end{tabular}

Data represent mean \pm SD of four separate experiments. The flux of $\mathrm{CO}$ and bilirubin was calculated from five separate experiments. $* P<0.01$ as compared with the control values. 

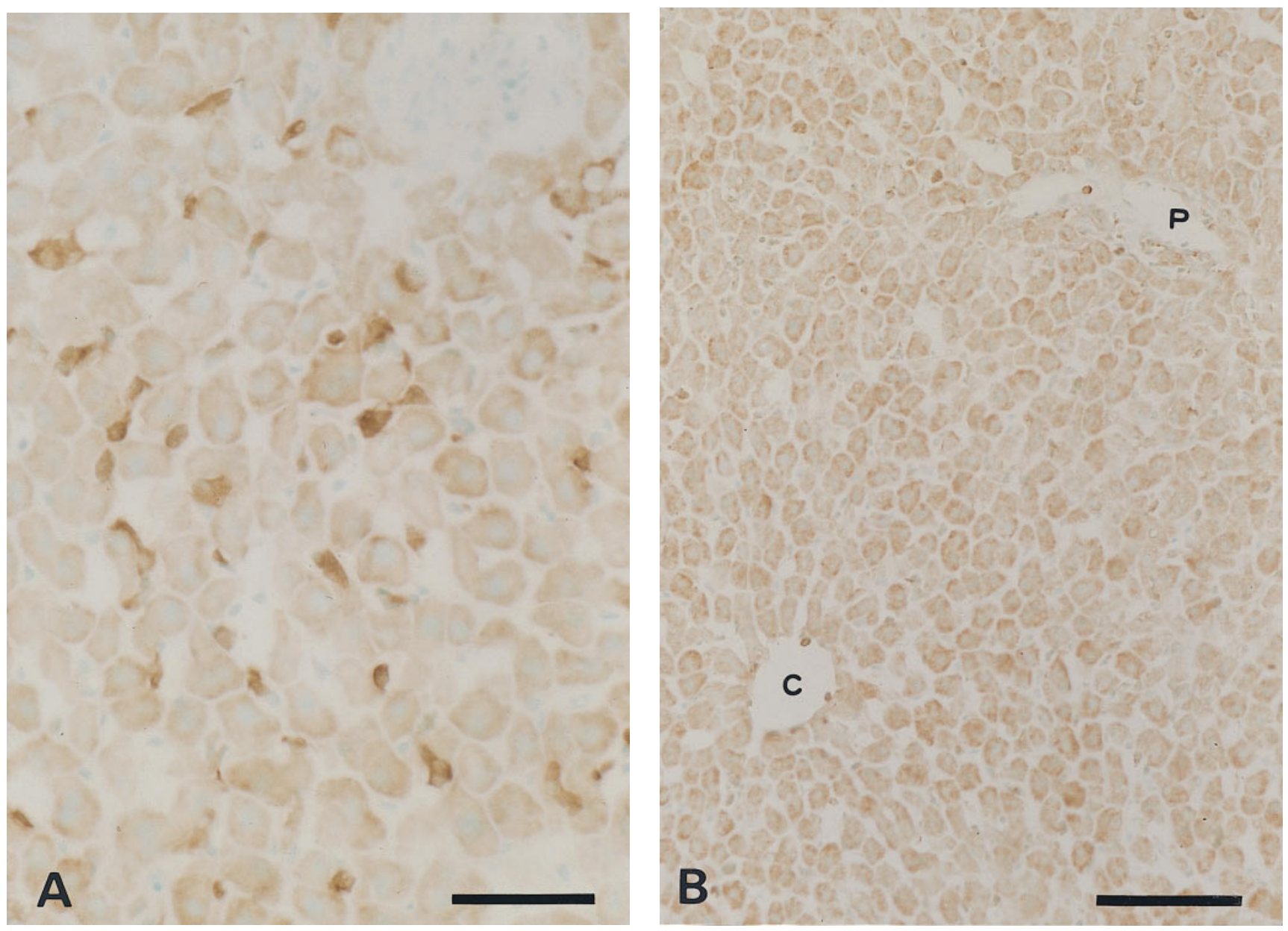

Figure 4. Immunohistochemical analysis of the expression of HO-1 and HO-2 in the liver sampled $6 \mathrm{~h}$ after treatment with intraperitoneal injection of lipopolysaccharide at $4 \mathrm{mg} / \mathrm{kg}$. $A$ and $B$ illustrate the liver sections stained with GTS-1 and GTS-2, respectively. Bars, $50 \mu \mathrm{m}$ and $100 \mu \mathrm{m}$ in $A$ and $B$, respectively. $P$ and $C$ denote portal and central venules, respectively.

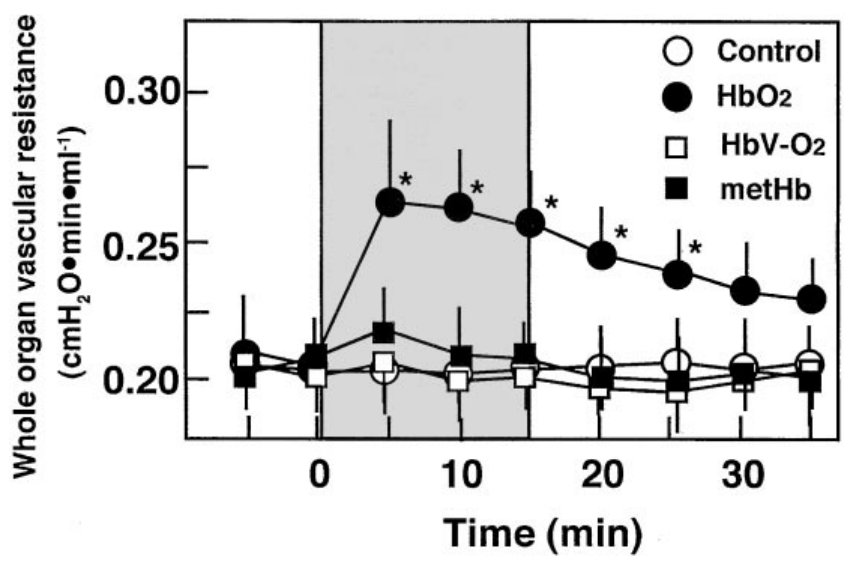

Figure 5. Time history showing effects of $\mathrm{Hb}$ derivatives on the whole organ vascular resistance in perfused rat liver. $\mathrm{The} \mathrm{Hb}$ derivatives $\left(\mathrm{HbO}_{2}, \mathrm{HbV}-\mathrm{O}_{2}\right.$, metHb) were administered at a final $\mathrm{Hb}$ concentration of $1.5 \mathrm{~g} / \mathrm{dl}$ for $15 \mathrm{~min}$ as seen in the shaded area. Data represent mean $\pm \mathrm{SE}$ of six experiments in each group. Open and closed circles indicate the data collected from the control and $\mathrm{HbO}_{2}$-treated livers, respectively. Open and closed squares are those collected from the groups treated with $\mathrm{HbV}-\mathrm{O}_{2}$ and metHb, respectively. $* P<0.05$ as compared with the data in the control group. vascular resistance under the current experimental conditions. To specify the role of $\mathrm{CO}$ generated in intra- and extravascular compartments, effects of $\mathrm{HbV}-\mathrm{O}_{2}$ on the vascular resistance were examined. As seen, $\mathrm{HbV}-\mathrm{O}_{2}$ administration did not evoke any significant elevation in the resistance. These results suggest that $\mathrm{HbO}_{2}$-induced elevation of the vascular resistance was abolished when diffusion of $\mathrm{Hb}$ across the sinusoidal endothelium into the space of Disse was blocked by its liposomal encapsulation.

We further examined the vascular responses at the level of hepatic sinusoids during the $\mathrm{HbO}_{2}$ administration using laser confocal microangiography in the perfused liver (Fig. 6). Administration of $\mathrm{HbO}_{2}$ induced a marked sinusoidal narrowing. The response was characterized by discontinuous patterns of narrowing in local sinusoidal segments colocalized with hepatic stellate cells that were able to be identified by vitamin A autofluorescence in their fat droplets. At the same time, several sinusoids exhibited continuous patterns of the decrease in their caliber. These findings were similar to those induced by $\mathrm{ZnPP}$, a heme oxygenase inhibitor, as previously reported (10). Such a heterogeneous feature of the sinusoidal responses was confirmed by morphometrical analysis comparing changes in the diameter measured at local sinusoidal segments colocal- 

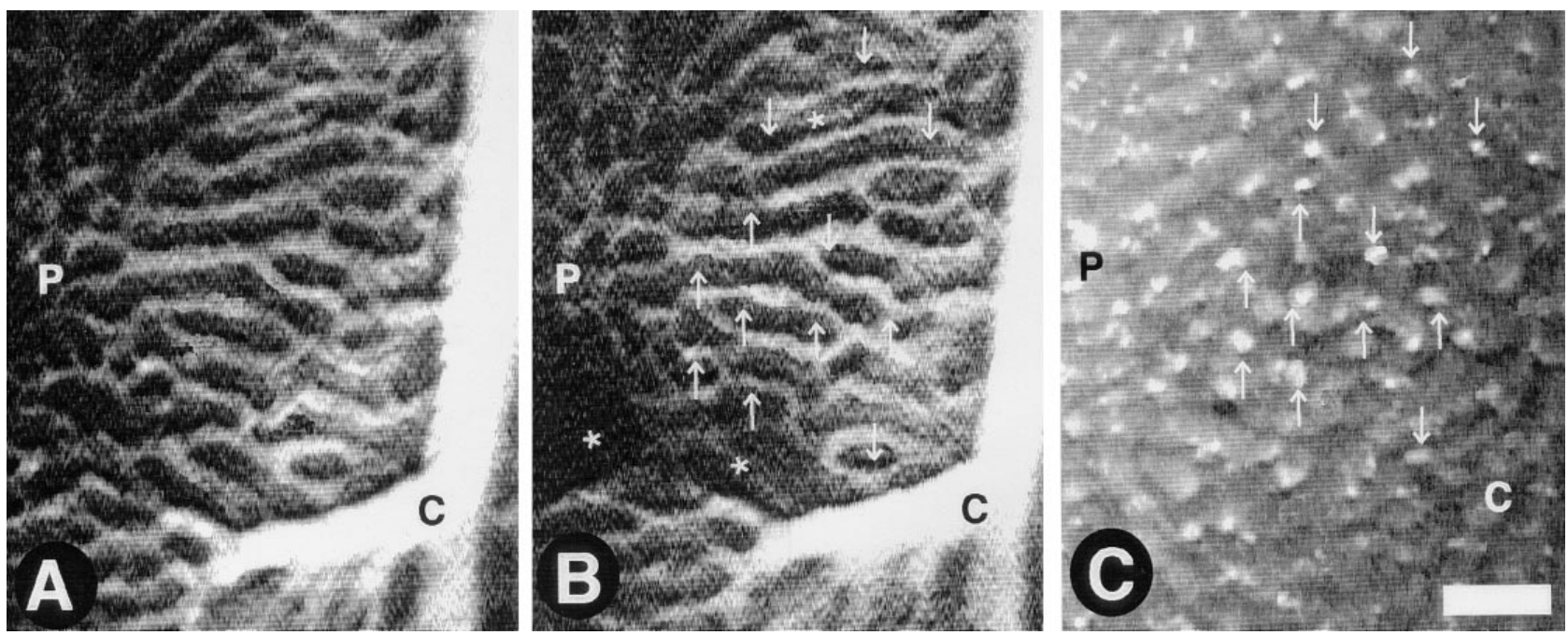

Figure 6. Representative microangiographs showing effects of $\mathrm{HbO}_{2}$ on sinusoidal caliber in the perfused rat liver. The buffer solution containing FITC-labeled dextran was injected transportally before $(A)$ and 5 min after the start of the $\mathrm{HbO}_{2}$ administration $(B)$ to visualize sinusoids. $C$ illustrates distribution of vitamin A autofluorescence as a landmark of hepatic stellate cells in the same microscopic field. $P$ and $C$ denote portal and central venules, respectively. Arrows denote local sinusoidal segments displaying narrowing responses corresponding to localization of hepatic stellate cells, while asterisks indicate those displaying a continuous pattern of narrowing or lack in filling of the fluorochrome. Bar, $100 \mu \mathrm{m}$.

ized with hepatic stellate cells to those measured at the segments without the cells (Table II). $\mathrm{HbO}_{2}$ administration induced an $\sim 10-20 \%$ decrease in the diameter, preferentially at the local sinusoidal segments colocalized with the stellate cellassociated vitamin A autofluorescence. On the other hand, sinusoidal narrowing responses were not evident in the groups treated with $\mathrm{HbV}-\mathrm{O}_{2}$. These results suggest that hepatic sinusoids constitute a vascular component responsible for the $\mathrm{HbO}_{2}$-elicited increase in the vascular resistance in perfused rat liver.

\section{Discussion}

The current study demonstrates for the first time that two distinct $\mathrm{HO}$ isoforms distribute in different kinds of cells in the liver: HO-1 in Kupffer cells, and HO-2 in parenchymal cells. We have recently shown that $\mathrm{CO}$ serves as an endogenous factor that actively lowers sinusoidal tone, and is necessary to guarantee ample blood supply into these vessels, in that elimination of $\mathrm{CO}$ by $\mathrm{ZnPP}$, a potent inhibitor of heme oxygenase, evoked a marked increase in baseline vascular resistance (10). The vascular component responsible for the increasing resistance appears to involve sinusoids inasmuch as these vessels displayed a discontinuous pattern of narrowing in response to $\mathrm{ZnPP}$ administration. The $\mathrm{ZnPP}$-elicited sinusoidal constriction is induced at least in part by the mechanisms involving hepatic stellate cells, microvascular pericytes occurring in the space of Disse (33) that are considered to be CO-sensing machinery for sinusoidal relaxation $(10,34)$. Importantly, supplementing $\mathrm{CO}$ at micromolar levels in the perfusate attenuated these changes elicited by $\mathrm{ZnPP}$. These results suggest that stellate cells account for an important cellular target that can respond to endogenously generated CO. However, there has been little information about the intrahepatic cellular components responsible for $\mathrm{CO}$ generation and their anatomical proximity to the stellate cells.
Although the present findings show that Kupffer cells and hepatocytes constitute a major cellular source of $\mathrm{HO}$, it remains unknown which cellular compartment plays a major role as an endogenous source of $\mathrm{CO}$ in the liver. According to the estimation of the $\mathrm{CO}$ flux determined in the isolated hepatocytes and its comparison to that in the perfused liver preparation, hepatocytes are likely to constitute a major cellular component for endogenous $\mathrm{CO}$ generation, and thus play an

Table II. Alterations in the Sinusoidal Caliber During Administration of $\mathrm{HbO}_{2}$ and $\mathrm{HbV}-\mathrm{O}_{2}$ in Perfused Rat Liver

\begin{tabular}{ccc}
\hline & \multicolumn{2}{c}{ Sinusoidal caliber } \\
\cline { 2 - 3 } Groups & $0 \mathrm{~min}$ & $5 \mathrm{~min}$ \\
\hline & $\mu m$ & $\mu m$ \\
$\mathrm{Control}$ & & $11.1 \pm 0.7$ \\
$\mathrm{HSC}(+)$ & $10.9 \pm 0.9$ & $11.3 \pm 0.6$ \\
$\mathrm{HSC}(-)$ & $11.1 \pm 0.5$ & \\
$\mathrm{HbO}_{2}$ & & $8.9 \pm 0.3^{* \ddagger}$ \\
$\mathrm{HSC}(+)$ & $10.7 \pm 0.7$ & $10.2 \pm 0.4^{\S}$ \\
$\mathrm{HSC}(-)$ & $11.0 \pm 0.5$ & $10.2 \pm 0.4$ \\
$\mathrm{HbV}-\mathrm{O}_{2}$ & & $10.4 \pm 0.3$ \\
$\mathrm{HSC}(+)$ & $10.3 \pm 0.5$ & \\
$\mathrm{HSC}(-)$ & $10.6 \pm 0.5$ & \\
\hline
\end{tabular}

Data represents mean $\pm \mathrm{SD}$ of more than 60 measurements from 4 separate liver preparations. HSC (+) and HSC (-) denote local sinusoidal segments colocalized with and without hepatic stellate cells (HSC). Measurements were carried out from FITC-dextran microfluorographs captured before $(0 \mathrm{~min})$ and $5 \mathrm{~min}$ after starting the administration of Hb derivatives. $* P<0.01$ as compared with the data collected from HSC (+) segments in the control group. ${ }^{\ddagger} P<0.01$ as compared with the data collected from HSC $(-)$ segments in the same group. ${ }^{\S} P<0.05$ as compared with the data measured at $0 \mathrm{~min}$ that were collected from HSC (-) segments in the same group. 
important role for endogenous $\mathrm{CO}$ generation. Furthermore, our findings obtained by using $\mathrm{Hb}$ derivatives suggest that elimination of $\mathrm{CO}$ in the extrasinusoidal space (e.g, the space of Disse) causes a marked sinusoidal constriction. In contrast to microvascular endothelium of other organs, sinusoidal endothelium possesses abundant small pores called fenestration. Since the size of the pores is no greater than $200 \mathrm{~nm}$ in diameter (27), free $\mathrm{Hb}$, but not $\mathrm{HbV}$, has a free access to the space of Disse.

It was previously reported that systemic administration of inhibitors of NO synthase evokes sinusoidal constriction in mice in vivo (35). However, when the absence of vasoconstrictive action of metHb, which can trap NO but not CO (36), is considered, the role of endogenously generated NO is unlikely to play a role with the previous results, showing that inhibitors of NO synthase do not induce vasoconstrictive changes in the isolated perfused liver (10). Taking these circumstances into account, we suggest that free $\mathrm{HbO}_{2}$ diffusing into the space of Disse eliminates CO in situ, and thereby evokes sinusoidal constriction.

In our earlier study, $\mathrm{ZnPP}$ was used to examine the role of $\mathrm{CO}$ in sinusoidal relaxation. It should be taken into account that $\mathrm{ZnPP}$ could increase the sinusoidal tone through direct inhibitory action on soluble guanylate cyclase (37) or inducible and neural NO synthases (38), or through activation of voltage-gated calcium channels (39). However, this possibility is unlikely to be involved (at least under our experimental conditions) when considering the following data: first, supplement of $\mathrm{CO}$ attenuated the ZnPP-induced increase in the resistance, and restored a reduction of tissue cGMP contents (11). Second, as discussed earlier, inhibitors of NO synthase did not increase the sinusoidal tone (10). Finally, we have recently shown that hepatic stellate cells in culture isolated from the intact liver exhibit little expression of the voltage-dependent $\mathrm{Ca}^{2+}$ channel (34). Furthermore, the present approach using different $\mathrm{Hb}$ derivatives that are able to eliminate or to maintain $\mathrm{CO}$ in situ without affecting the enzyme activity of $\mathrm{HO}$ convinced us that the action of $\mathrm{ZnPP}$ on sinusoidal tone is ascribable mainly to elimination of $\mathrm{CO}$. There is still a possibility that the $\mathrm{Hb}$ derivatives per se exert vasoconstrictive actions through the $\mathrm{CO}$-independent mechanisms such as stimulation of $\alpha$-adrenergic receptors (40). However, the data illustrating distinct vasoconstrictive responses among $\mathrm{HbO}_{2}$, metHb, and $\mathrm{HbV}$, together with our previous finding that phenylephrine, an $\alpha_{1}$ agonist, evokes constriction of portal vessels rather than sinusoids (10), leads us to suggest that involvement of such CO-independent mechanisms appear to be little, if any.

Considering the microanatomical orientation of the liver cells in and around sinusoids, HO-2 in hepatocytes stands in the reasonable position where the released $\mathrm{CO}$ can directly influence the contractile function of hepatic stellate cells located adjacent to the parenchymal region. On the other hand, $\mathrm{CO}$ released from HO-1 in Kupffer cells could easily be trapped by $\mathrm{HbO}_{2}$ present in the circulating erythrocytes, and is therefore unlikely to exert its action on the stellate cells that occur in the extrasinusoidal space. In this context, at least in the ex vivo perfusion system, the current data show physiological significance of extrasinusoidal CO-mediated mechanisms for microvascular relaxation, and thus suggest that $\mathrm{CO}$ derived from HO-2 in the hepatocytes contributes to active relaxation of the sinusoids to a greater extent than that derived from HO-1 in Kupffer cells. It is, however, still unknown whether $\mathrm{CO}$ de- rived from HO-1 plays a role in regulation of sinusoidal tone under physiological conditions in vivo, since Kupffer cells can obtain greater amounts of heme substrates from the portal circulation (e.g., senescent erythrocytes). It should therefore be necessary to study whether these macrophages might use $\mathrm{CO}$ generated by HO-1 to control sinusoidal perfusion.

When the previously proposed mechanisms for intrahepatic heme degradation are taken into account, the present findings suggest a possible cooperative role of these two isoforms in catabolism of hemoglobin-derived heme in different cellular compartments. Namely, previous studies by Bissel et al. (41) revealed that removal of senescent erythrocytes from the circulation is carried out by macrophages in the liver and spleen, while hemoglobin released as a consequence of erythrocyte destruction can be metabolized mainly in the liver parenchyma. Spontaneous expression of the inducible $\mathrm{HO}$ isoform in Kupffer cells of the control liver appears to result from constant exposure of the cells to senescent erythrocytes in the sinusoidal compartment inasmuch as such an expression of HO-1 is evident as well in macrophages in red pulp of spleen, another major compartment for erythrocyte removal and heme degradation (2). On the other hand, the liver parenchyma is considered to be a major cellular compartment for localization of nonhemoglobin heme proteins, including cytochrome P450 (42). Since heme molecules of these enzymes are known to be metabolized exclusively by the heme oxygenase reaction (2), it is not unreasonable to suggest that, in the normal liver, HO-2 limits intrahepatic turnover of the heme enzymes.

Several studies have recently suggested a protective role of HO-1 induction against cell and tissue damages in that a decrease in free heme as well as an increase in bilirubin production help minimize oxidant-dependent cytotoxicity under disease conditions such as endotoxemia $(43,44)$. However, it is still unknown in the liver whether such HO-1-mediated upregulation in heme degradation is beneficial in protecting the tissue from oxidative stress. In conjunction with our recent observation that CO serves as a cholestatic factor (11), over expression of HO-1 may lead to hepatobiliary complications including hyperbilirubinemia and cholestasis, which could also occur clinically in endotoxemia $(45,46)$. Thus, pathophysiological significance of the inducible $\mathrm{HO}$ isozyme in the liver should be examined further under various disease conditions.

\section{Acknowledgments}

The authors thank Drs. Shinji Sakamoto, Katsunari Tedzuka, Tsuyoshi Sano, and Masaya Shiomi for technical assistance. We also thank the late Professor Emeritus Benjamin W. Zweifach for his suggestion to prepare the manuscript.

This work was supported by Grant-in-Aid for Scientific Research from the Ministry of Education, Science, and Culture of Japan (09470143, 07508005), and by grants from Keio University School of Medicine, Research Foundation for Opto-Science and Technology, and in part by Surveys and Research on Specific Diseases from the Ministry of Health (1996 and 1997). Nobuhito Goda is a research fellow supported by the Japan Society for the Promotion of Science in 1997.

\section{References}

1. Shibahara, S., R. Müller, H. Taguchi, and T. Yoshida. 1985. Cloning and expression of cDNA of rat heme oxygenase. Proc. Natl. Acad. Sci. USA 82: 
7865-7869.

2. Maines, M.D. 1988. Heme oxygenase: function, multiplicity, regulatory mechanisms, and clinical applications. FASEB J. 2:2557-2568.

3. Ewing, J.F., and M.D. Maines. 1991. Rapid induction of heme oxygenase 1 mRNA and protein by hyperthermia in rat brain: heme oxygenase 2 is not a heat shock protein. Proc. Natl. Acad. Sci. USA. 88:5364-5368.

4. Rizzardini, M., M. Terao, F. Falciani, and L. Cantoni. 1993. Cytokine induction of haem oxygenase mRNA in mouse liver. Biochem. J. 290:343-347.

5. Maines, M.D., and A. Kappas. 1977. Metals as regulators of heme metabolism: physiological and toxicological implications. Science. 198:1215-1221.

6. Kurata, S., M. Matsumoto, Y. Tsuji, and H. Nakajima. 1996. Lipopolysaccharide activates transcription of the heme oxygenase gene in mouse M1 cells through oxidative activation of nuclear factor кB. Eur. J. Biochem. 239:566571.

7. Tacchini, L., L. Schiaffonati, C. Pappalardo, C. Gatti, and A. BernelliZazzera. 1993. Expression of HSP 70, immediate-early response and heme oxygenase genes in ischemia-reperfused rat liver. Lab. Invest. 68:465-471.

8. Cruse, I., and M.D. Maines. 1988. Evidence suggesting that the two forms of heme oxygenase are products of different genes. J. Biol. Chem. 263:33483353 .

9. Suematsu, M., S. Kashiwagi, T. Sano, N. Goda, Y. Shinoda, and Y. Ishimura. 1994. Carbon monoxide as an endogenous modulator of hepatic vascular perfusion. Biochem. Biophys. Res. Commun. 205:1333-1337.

10. Suematsu, M., N. Goda, T. Sano, S. Kashiwagi, Y. Shinoda, and Y. Ishimura. 1995. Carbon monoxide: an endogenous modulator of sinusoidal tone in the perfused rat liver. J. Clin. Invest. 96:2431-2437.

11. Sano, T., M. Shiomi, M. Wakabayashi, Y. Shinoda, N. Goda, T. Yamaguchi, Y. Nimura, Y. Ishimura, and M. Suematsu. 1997. Endogenous carbon monoxide suppression stimulates bile acid-dependent biliary transport in perfused rat liver. Am. J. Physiol. 272(35):G1268-G1275.

12. Stocker, R., A.N. Glazer, and B.N. Ames. 1987. Antioxidant activity of albumin-bound bilirubin. Proc. Natl. Acad. Sci. USA. 84:5918-5922.

13. Yamaguchi, T., F. Horio, T. Hashizume, M. Tanaka, S. Ikeda, A. Kakinuma, and H. Nakajima. 1995. Bilirubin is oxidized in rats treated with endotoxin and acts as a physiological antioxidant synergistically with ascorbic acid in vivo. Biochem. Biophys. Res. Commun. 214:11-19.

14. Oshio, C., and M.J. Phillips. 1981. Contractility of bile canaliculi: implications of liver function. Science. 212:1041-1042.

15. Rotenberg, M.O., and M.D. Maines. 1990. Isolation, characterization and expression in Escherichia coli of a cDNA encoding rat heme oxygenase-2. J. Biol. Chem. 265:7501-7506.

16. Ohashi, H., K. Maruyama, Y. Liu, and A. Yoshimura. 1994. Ligandinduced activation of chimeric receptors between the erythropoietin receptor and receptor tyrosine kinases. Proc. Natl. Acad. Sci. USA. 91:158-162.

17. Suda, T., T. Takahashi, P. Golstein, and S. Nagata. 1993. Molecular cloning and expression of the Fas ligand, a novel member of the tumor necrosis factor family. Cell. 75:1169-1178.

18. Yoshida, T., and G. Kikuchi. 1978. Reaction of the microsomal heme oxygenase with cobaltic protoporphyrin IX, an extremely poor substrate. $J$. Biol. Chem. 253:8479-8482.

19. McKinney, M.M., and A. Parkinson. 1987. A simple, nonchromatographic procedure to purify immunoglobulins from serum and ascites fluid. $J$. Immunol. Methods. 96:271-278.

20. Yamamoto, T., M. Naito, H. Moriyama, H. Umezu, H. Matsuo, H. Kiwada, and M. Arakawa. 1996. Repopulation of murine Kupffer cells after intravenous administration of liposome-encapsulated dichloromethylene diphosphonate. Am. J. Pathol. 149:1271-1286.

21. Yamaguchi, T., Y. Wakabayashi, M. Tanaka, T. Sano, H. Ishikawa, H. Nakajima, M. Suematsu, and Y. Ishimura. 1996. Taurocholate induces directional transport of bilirubin into bile in the perfused rat liver. Am. J. Physiol. 270:G1028-G1032.

22. Falkenberg, F.W., H. Weichert, M. Krane, I. Bartels, M. Palme, H.O. Nagels, and H. Fiebig. 1995. In vitro production of monoclonal antibodies in high concentration in a new and easy to handle modular minifermentor. J. Immunol. Methods. 179(1):13-29.

23. Sakai, H., S. Takeoka, H. Yokohama, Y. Seino, H. Nishide, and Y. Tsuchida. 1993. Purification of concentrated hemoglobin using organic solvent and heat treatment. Prot. Expr. Pur. 4:563-569.

24. Sakai, H., K. Hamada, S. Takeoka, H. Nishide, and E. Tsuchida. 1996. Physical properties of hemoglobin vesicles as red cell substitutes. Biotechnol.
Prog. 12:119-125.

25. Rudolph, A.S., H. Spielberg, B.J. Spargo, and N. Kossovsky. 1995. Histopathologic study following administration of liposome-encapsulated hemoglobin in the normovolemic rats. J. Biomed. Mater. Res. 29:189-196.

26. Naito, M., and E. Wisse. 1978. Filtration effect of endothelial fenestrations on chylomicron transport in neonatal rat liver sinusoids. Cell Tissue Res. 190:371-382.

27. Wisse, E., R.B. DeZanger, K. Charels, P. van der Smissen, and R.S. McCuskey. 1985. The liver sieve: considerations concerning the structure and function of endothelial fenestrae, the sinusoidal wall and the space of Disse. Hepatology. 5:683-692.

28. Stock, R.J., E.V. Cilento, and R.S. McCuskey. 1989. A quantitative study of fluorescein isothiocyanate-dextran transport in the microcirculation of the isolated perfused rat liver. Hepatology. 9:75-82.

29. Iigou, Y., M. Suematsu, T. Higashida, J. Oheda, K. Matsumoto, Y. Wakabayashi, Y. Ishimura, M. Miyasaka, and T. Takashi. 1997. In vivo constitutive expression of ICAM-1 in rat microvascular systems analyzed by laser confocal microscopy. Am. J. Physiol. 273:H138-H147.

30. Suematsu, M., M. Oda, H. Suzuki, H. Kaneko, N. Watanabe, T. Furusho, S. Masushige, and M. Tsuchiya. 1993. Intravital and electron microscopic observation of Ito cells in rat hepatic microcirculation. Microvasc. Res. 46:28-42.

31. Ewing, J.F., and M.D. Maines. 1995. Distribution of constitutive (HO-2) and heat-inducible (HO-1) heme oxygenase isozymes in rat testes: HO-2 displays stage-specific expression in germ cells. Endocrinology. 136:2294-2302.

32. Knook, D.L., and A.M. De Leeuw. 1982. Connective tissue of the normal and fibrotic human liver. Thieme, Stuttgart. 67-71 pp.

33. Wake, K. 1980. Perisinusoidal stellate cells (fat-storing cells, interstitial cells, lipocytes), their related structure in and around the liver sinusoids, and vitamin A-storing cells in extrahepatic organs. Int. Rev. Cytol. 66:303-353.

34. Kashiwagi, S., M. Suematsu, Y. Wakabayashi, N. Kawada, M. Tachibana, A. Koizumi, M. Inoue, Y. Ishimura, and A. Kaneko. 1997. Electrophysiological characterization of cultured hepatic stellate cells in rats. Am. J. Physiol. 272 (35):G742-G750.

35. Nishida, J., R.S. McCuskey, D. McDonnell, and E.S. Fox. 1994. Protective role of NO in hepatic microcirculatory dysfunction during endotoxemia. Am. J. Physiol. 267:G1135-G1141.

36. R.F. Eich, T. Li, D.D. Lomon, D.H. Doherty, S.R. Curry, J.F. Aitken, A.J. Mathews, K.A. Johnson, R.D. Smith, G.N. Phillips, and J.S. Olson. 1996. Mechanism of NO-induced oxidation of myoglobin and hemoglobin. Biochemistry. 35:6976-6983.

37. Ignarro, L.J., B. Barrot, and K.S. Wood. 1984. Regulation of soluble guanylate cyclase activity by porphyrins and metalloporphyrins. J. Biol. Chem. 259:6201-6207.

38. Wolff, D.J., R.A. Naddelman, A. Lubeskie, and D.A. Saks. 1996. Inhibition of nitric oxide synthase isoforms by porphyrins. Arch. Biochem. Biophys. 333:27-34.

39. Linden, D.J., K. Narasimhan, and D. Gurfel. 1993. Protoporphyrins modulate voltage-gated Ca current in AtT-20 pituitary cells. J. Neurophysiol. 70:2673-2677.

40. Gulati, A., and A.C. Sharma. 1994. Prazosin blocks the pressor but not the regional circulatory effects of diaspirin crosslinked hemoglobin. Life Sci. 55 121-130.

41. Bissell, D.M., L. Hammaker, and R. Schmid. 1972. Hemoglobin and erythrocyte catabolism in rat liver: the separate roles of parenchymal and sinusoidal cells. Blood. 40:812-822.

42. Kutty, R.K., R.F. Daniel, D.E. Ryan, W. Levin, and M.D. Maines. 1988. Rat liver cytochrome P-450b, P-420b, and P-420 $c$ are degraded to biliverdin by heme oxygenase. Arch. Biochem. Biophys. 260:638-644.

43. Choi, A.M.K., and J. Alam. 1996. Heme oxygenase-1: function, regulation, and implication of a novel stress-inducible protein in oxidant-induced lung injury. Am. J. Respir. Cell Mol. Biol. 15:9-19.

44. Camhi, S.L., J. Alam, L. Otterbein, S.L. Sylvester, and A.M.K. Choi. 1995. Induction of heme oxygenase-1 gene expression by lipopolysaccharide is mediated by AP-1 activation. Am. J. Respir. Cell Mol. Biol. 13:387-398.

45. Roelofsen, H., C.N. Van Der Veere, R. Ottenhoff, B. Schoemaker, P.L.M. Jansen, and R.P.J. Oude Elferink. 1994. Decreased bilirubin transport in the perfused liver of endotoxemic rats. Gastroenterology. 107:1075-1084.

46. Roelofsen, H., B. Schoemaker, R. Ottenhoff, P.L.M. Jansen, and R.P.J. Oude Elferink. 1995. Impaired hepatocanalicular organ anion transport in endotoxemic rats. Am. J. Physiol. 269:G427-G434. 